\title{
Public Policy Analysis in Iran: The Partial Least Square Test
}

\author{
Completed Research Paper \\ Roya Asadifard \\ Tarbiat Modares University (TMU) \\ roya.asadifard@yahoo.com
}

\begin{abstract}
This research tests Iranian public policy analysis model. This model is a descriptive and qualitative model that created through grounded theory approach and then used Partial Least Square for confirmation test and explore predictability of it. The results confirm that public policy analysis model of Iran have three dimension of formulation analysis, implementation analysis and evaluation analysis which these components have influence together sequently.
\end{abstract}

Keywords: Public Policy, Public Policy Analysis, Grounded Theory, Partial Least Squares. 


\section{Introduction}

During the last decades public policy making system of Iran has been tried to apply and contextualize multidisciplinary public policy sciences. Accordingly public policies analysis running in based on traditional customs and tools now. Therefore it is obvious public policy analysis occurs in that manner and with tacit knowledge or even common sense, for example when a Representative of the public asks a question from the Minster about implementation of the policy in Islamic Assembly Majlis, she/he carries out public policy analysis in practice. Given these current circumstances of public policy making entails existence of a scientific framework for public policy analysis in Iran. Thus at first this research designed to finding out a public policy analysis framework. As in the discovery stage Grounded Theory methodology has been used. In the next step our purpose is confirmation and explanatory power and prediction test of obtained framework through GT. As if the research objective is prediction and theory development, then the appropriate method is PLS-SEM. Conceptually and practically, PLS-SEM is similar to using multiple regression analysis (Hair et al., 2011). Another powerful feature of PLS path modeling is that it is suitable for prediction-oriented research (Henseler et al., 2009). The because of this possibilities of PLS this research have used Partial Least Square method by use of SmartPLS software(Ringle et al., 2005) for confirmation and theory development of Iranian public policy analysis model which is created via grounded theory. Thus after a brief review of literature on public policy analysis, Iranian public analysis model is introduce. Then path model is present which indicates results of PLS tests.

\section{Literature Review and Research Hypotheses}

\subsection{Public Policy Analysis}

The term policy analysis covers many different activities. It may mean examining the component of the policy making process, such as policy formulation and implementation, or studying substantive public policy issues. Most often policy analysis refers to the assessment of policy alternatives. So policy analysis is not intended to make policy decisions but rather to inform the process of public deliberation and debate (Kraft and Furlong, 2011: 98). In one hand Policy analysis can never be reduced to a formula for solving public problems, but it can bring valuable information to both policy makers and the public (Ibid:99). In other hand Policy analysis and programs evaluation are distinct, although related activities (Wiemer and Vining, 2011:343). Policy analysis is an art. Its subjects are public problems that must be solved at least tentatively to be understood (Wildavsky, 1979). Policy analysis is an approach to public policy that aims to integrate and contextualize models and research from those disciplines which have a problem and policy orientation(Parsons, 2005:xv) and consists in the study of the action of public authorities within society(Knoepfel et al., 2007: 3). Policy analysis is a process of multidisciplinary inquiry designed to create, critically assess, and communicate information that is useful in understanding and improving policies (Dunn, 2007: 1). And what governments do, why they do it, and what difference it makes (Dye, 2008:1). In other word policy analysis is a technique which uses data or takes decisions about it, estimate and measure public policy consequences (Sapru, 2010: 45). Furthermore these definitions some authors introduce models to study and practice of public policy analysis which we consider these main approaches in continue.

\subsection{The process of integrated policy analysis}


Dunn (2007) defines policy analysis based on policy relevant information and transformation of that information which carries out by analysis methods as he has called. In this framework policy analysis address five types of questions: what is the problem for which a solution is sought?, what course of action should be chosen to solve the problem?, what are the outcomes of choosing that course of action?, Does achieving theses outcomes help to solve the problem?, what future outcomes can be expected if other course of action are chosen?. Thus answers to these questions require five types of policy-relevant information, or what we may call policy-informational components. These components request information about policy problem, policy performance, expected policy outcomes, preferred policies, and observed policy outcomes. The five types of policy-relevant information are independent and the five types of information are produced and transformed by using methods of policy analysis. These methods include monitoring (description) produces information about observed policy outcomes. Forecasting (prediction) produces information about expected policy outcomes. Evaluation (appraisal) produces information about the value of observed and expected policy outcomes. Recommendation (prescription) produces information about perfected policies. Problem structuring (definition) produces information about what problem to solve (Dunn, 2007: 3-6).

\subsection{Public policy analysis phases}

The proposed method of policy analysis by Knopefel and his colleagues (2007) lay on three definitive analytical areas that is, the interaction between public and private actors, public problems and comparative analysis, and they divide public policy process to 5 phases and analyst should be follow main questions in phases: emergence of problem: how is an awareness of the problem reached? ( $1^{\text {st }}$ phase). Agenda setting: what are the factors that will make the government act in response to the problem? $\left(2^{\text {nd }}\right.$ phase). Formulation and adoption of the policy programs: what are the solutions proposed and accepted by the government and parliament? On the basis of which process are these solutions formulated? ( ${ }^{\text {rd }}$ phase). Policy implementation: have the decisions of legislature and the government been implemented? $\left(4^{\text {th }}\right.$ phase). Policy evaluation: what are the direct and indirect effects of the policy? $\left(5^{\text {th }}\right.$ phase)(Knopefel et al., 2007:31).

\subsection{Rationalist Mode of Analysis}

Wiemer and Vining (2011) provide a perceptual picture of the policy analysis process. It divides the process into two major components- problem analysis and solution analysis- both of which are vital. Problem analysis consists of three major steps :( P1) understanding the problem, $(\mathrm{P} 2)$ choosing and exploring relevant policy goals and constraints, and (P3) choosing a solution method. Solution analysis consists of (S1) choosing impact categories for goals, (S2) concretely specifying policy alternatives, (S3) predicting impacts of alternatives, (S4) valuing impacts of alternatives, (S5) assessing and recommending to conveying useful advice to clients. Also Kraft and Furlong (2011:100-101) propose rational model to policy analysis. They argue the most common approach to policy analysis is to picture it as a series of analytical steps or stages, which are the elements in rational problem solving. According to models of rational decision making, one defines a problem, indicates the goals and objectives to be sought, considers a range of alternative solutions, evaluate each of the alternatives to clarify their consequences, and the recommends or chooses the alternative with the greatest potential for solving the problem. 


\subsection{Public policy analysis model in Iran}

Public policy analysis model in Iran created through Grounded Theory approach which obtained 792 theoretical codes in open coding phase by interviews with policy makers which includes: Representatives of people in the parliament, current and in time, and experts of Research Center of Parliament (as formulators and legislators of policies), Ministers and Vise ministers(current and in time as implementers of policies), and managers of General Inspection Organization and Guardian Council members(as evaluators of policies). This procedure of sampling was carried out to occupy perspectives of all of public policy makers to create a public policy analysis model. In sum 40 interviews have been taked during two years (2010-2012). these codes cumulated around four axial codes that is formulation analysis, implementation analysis, evaluation analysis and public policy analysis criteria and sequently concepts of "adjustment", "commitment to implementation", "evaluation system" and "realness" are selective categories of formulation analysis, implementation analysis, evaluation analysis and public policy analysis criteria which constitute operational variables of indicators and constructs of the lower abstraction level of model. At the step one this model is descriptive, integrated, fact-finding, policy based process, functional, longitudinal analysis and snapshot analysis and applicable to different policy areas. It describes how to do public policy analysis function and indicate start and end point of analysis to continue analysis for policy learning, improvement and termination. As states that Public policy analysis process in Iran has three dimensions which are: 1 . Formulation analysis; 2 . Implementation analysis; 3. Evaluation analysis and a semidimension as public policy analysis criteria. To reminder public policy analysis criteria are not policy making necessities or even policy evaluation criteria (Dunn, 2007:354; Kraft and Furlong, 2010:154) these criteria use to analysis process and in this model are: realness, social justice, public interest, national interest, the public satisfaction, cost-benefit/effectiveness analysis, feasibility. During distribution of questionnaires to participants of research, one of them emphasize to a criteria in public policy analysis and believed this criteria should be considered in all stages of analysis process so because of Glaser (2002) advises that "one is enough if it is significant" and one concept can contribute to the emerging theory, concept of 'cultural and Islamic values and ethics' considered in the final conceptual research model. Also this model has concepts that are not parts of public policy analysis factors but are prerequisites' of public policy making systems and influence to public policy analysis which are 'active participation of related groups', 'intelligent information' and 'policy research' that have been mentioned by participants of the research. Figure 1 indicates components of this model that will be tested using PLS. As this study tests significance of dimensions and cause-effect relationships between research model dimensions and its semidimensions to examine exploratory and predictive power of our qualitative model by empirical test and to theory confirmation test. 


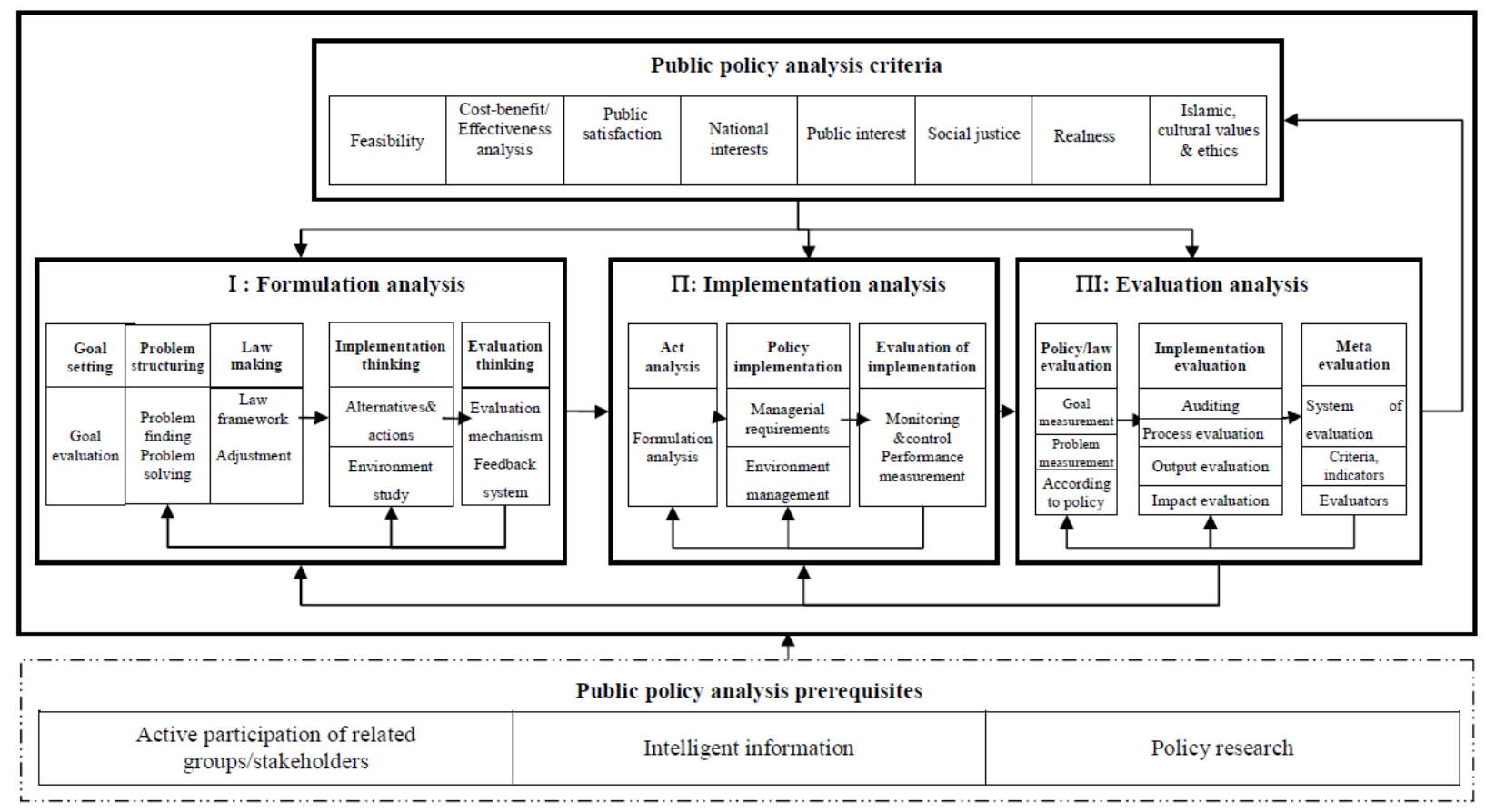

Figure 1: Public policy analysis model in Iran 
Thus in the base of theoretical model we can assume these hypotheses:

$H_{1}$ : Public policy analysis model have three significant dimensions of 'Formulation analysis', 'Implementation analysis' and 'Evaluation analysis'.

$\mathrm{H}_{2}$ : Formulation analysis has influence on Public policy analysis.

$\mathrm{H}_{3}$ : Formulation analysis has influence on Implementation analysis.

$H_{4}$ : Formulation analysis has influence on Evaluation analysis.

$H_{5}$ : Implementation analysis has impact on Public policy analysis.

$H_{6}$ : Implementation analysis has impact on Evaluation analysis.

$H_{7}$ : Evaluation analysis has effect on Public policy analysis.

$H_{8}$ : Criteria have impact on Formulation analysis.

$H_{9}$ : Criteria have impact on Implementation analysis.

$H_{10}$ : Criteria have impact on Evaluation analysis.

$H_{11}$ : Prerequisites have influence on Public policy analysis.

These hypotheses reflect our conceptual framework for empirical test. In other word we transfer descriptive and qualitative public policy analysis model to statistical hypotheses which is test in the next section of this paper.

\section{PLS path model analysis}

\subsection{Design of data gathering}

To test the model, questionnaires designed ( 5 point likert scale) and presented among 145 policy makers and academicians (65 academicians and the rest policy actors) in order to confirmation of validity of the model and test of the proposed model. Only fully answered questionnaires- 90 from 145 - were included in the PLS analysis of the causal model.

\subsection{Evaluation of Measurement Model}

Applying the PLS algorithm requires an extensive model evaluation. Specifically, the extent to which a specified model is appropriate for describing the effects between the constructs under investigation needs to be demonstrated. So we should simplisize and draw path model scheme of qualitative public policy analysis model at first. The path model in Figure 2 summaries the Partial Least Square (PLS) path model. In this path model we have inner model and outer model: The inner model specifies the relations between unobserved or latent variables, while the outer model specifies the relations between a latent variable and its observed indicators or manifest variables. 


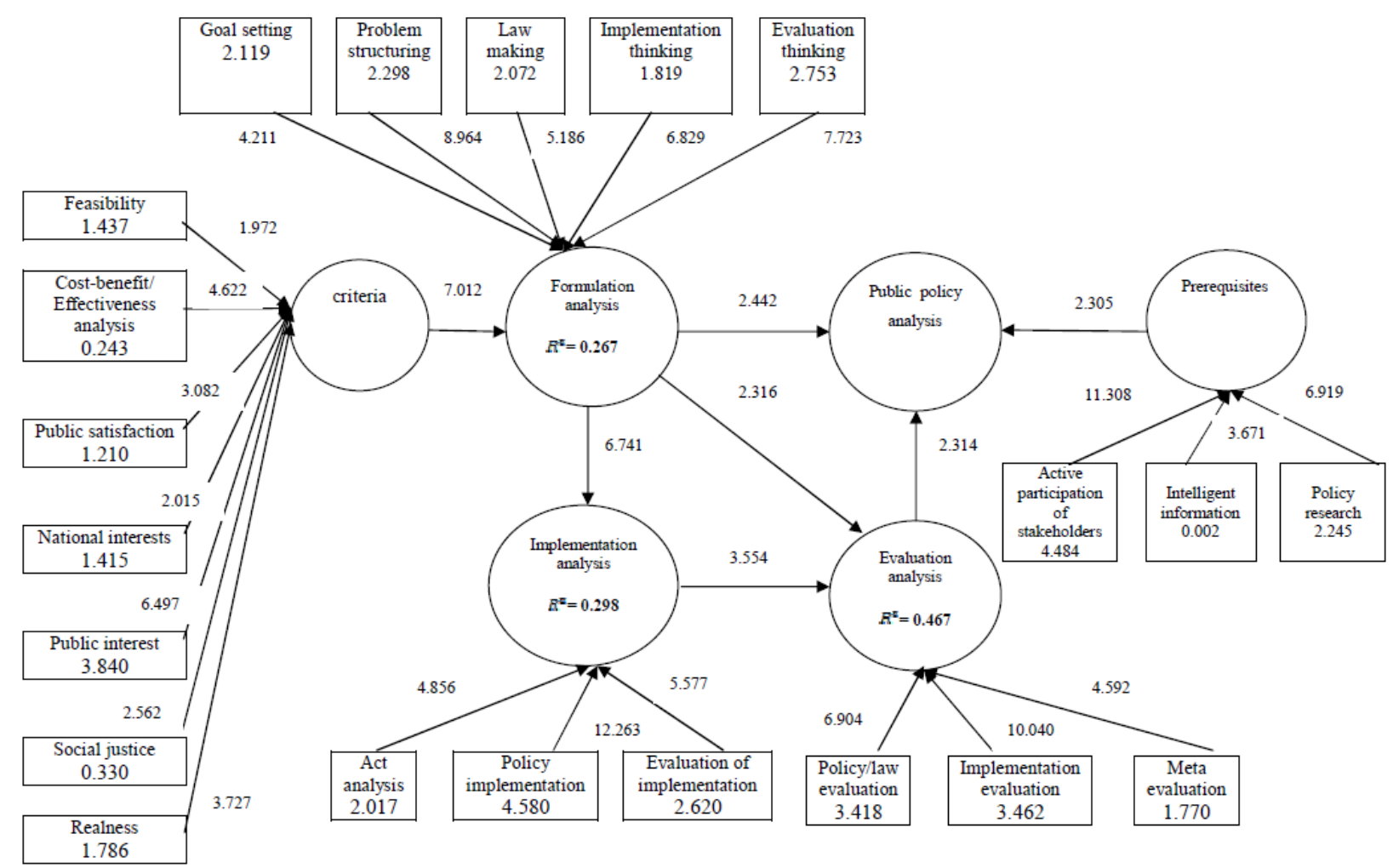

Figure 2: Path model $\left(R^{2}\right.$, Weights, Path coefficients $)$ 
Based on theoretical considerations our model imply to formative indicators because formative indicators are assumed to cause a latent as a proxy for the latent construct (Götz et al., 2010:697; Hair et al., 2011) and indicators determine the structural model and changes in those indicators cause to changes in the structural model (Hanafizade and Rahmani, 2010:51). Then designing formative model of public policy analysis in SmartPLS software environment is use for structural measurement model test. By examining different designs try to draw the measurement model which can be explain most amounts of $R 2$. Then "PLS algoritms" are implement.

\subsection{Evaluation of the Structural Model}

We start by looking at the R-squares for each dependent LV (Latent Variable) in the structural model provided by PLS. $R 2$ values express the proportion the endogenous latent variables' explained variance. In the structural model, $R 2$ values of $0.75,0.50$, or 0.25 for endogenous latent variables can be regarded as substantial, moderate or weak (Hair, et al, 2011). As explained variance of constructs indicate public policy analysis variance explained by $\% 26$ by formulation analysis, $\% 29$ by implementation analysis, $\% 46$ by evaluation analysis which are weak, weak and moderate. Thus we can result that evaluation analysis have most prediction power on public policy analysis. Then tests perform for loading and weights. For formative items, the magnitude and significance of the weight indicate the importance of the contribution of the associated latent variable. Bootstrapping test carried out for path coefficients structural model. Paths of 'Formulation Analysis -> Implementation Analysis' and 'Implementation Analysis -> Evaluation Analysis' have highest weight (6.741), (3.554) and both evidence to high significant at 0.001 level. Thus these results imply to acceptance of $\mathrm{H}_{3}$ , $\mathrm{H}_{6}$ research hypotheses. Paths of 'Formulation Analysis -> Policy Analysis' and 'Formulation Analysis -> Evaluation Analysis' have weight of (2.442) and (2.3.16) and are significant at level of 0.05 , thereby hypotheses of $H_{2}, H_{4}$ are confirm. Path of 'Evaluation Analysis -> Policy Analysis' has weight and t-value of (2.314) and (1.677) so we can confirm $\mathrm{H}_{7}$ research hypothesis at the significant level of 0.1 . Among all impact path of Criteria to constructs of the model only path of 'Criteria -> Formulation Analysis' with high weight of (7.012) and evidence to high significant level of 0.001 which show to confirmation of $H_{8}$. Also path of 'prerequisites -> Policy Analysis' is significant at the 1.65 level and we can confirm $H_{11}$ research hypothesis and conclude that prerequisites of public policy making have impact on public policy analysis. All constructs have significant effect on policy analysis except 'Implementation Analysis -> Policy Analysis' which have not significant t-values. Then by omit of this causal effect, we compute effect size $f^{2}$ for 'implementation analysis'.

$$
f^{2}=\frac{\mathrm{R}^{2} \text { included }-\mathrm{R}^{2} \text { excluded }}{1-\mathrm{R}^{2} \text { included }}
$$

values of $0.02,0.15$, and 0.35 can be viewed as a gauge for whether a predictor latent variable has a small, moderate, or large effect at the structural level. Value of $f^{2}$ is $0 / 0192$ that is a small value. Of course it is important to understand that a small $f^{2}$ does not necessarily imply an unimportant effect (Wilson, 2010:643).

Indicator reliability in the assessment of formative measurement models compare each indicator's weights by means of the PLS approach. One could thus determine which indicators contribute most substantially to the construct ("indicator relevance"). Formative constructs' valid indicators can reveal positive, negative or no correlations. Consequently, the different indicators' weights are not interpreted as factor loadings, but should rather be compared to 
determine their relative contribution to the relevant construct (Götz et al., 2010:698). The results of this test in PLS exhibit that indicator variable of 'evaluation thinking' has highest weight (2.753) in the construct of 'Formulation analysis' in respect to formative measurement structural model and furthermore all its indicators evidence high significant at the $p<0.001$ level. Indicator variable of 'policy implementation' has highest weight (4.580) in the construct of 'Implementation analysis' and all indicators of it evidence high significant at the $p<0.001$ level. Indicator variables of 'implementation evaluation' and 'policy/law evaluation' have highest weight of (3.462) and (3.418) in the construct of 'evaluation analysis' and all indictors of this construct imply to high significant at the $\mathrm{p}<0.001$ level. Among indicator variables of 'Criteria', 'public interest' has highest weight (3.840) and indicates to high significance at $\mathrm{p}<0.001$ level but all of other indicators are significant at $\mathrm{p}<0.05$ level. Prerequisite of 'active participation of stakeholders' has highest weight (4.484) in the prerequisites construct of structural model and other indicators show to high significant at $\mathrm{p}<0.001$ level.

Furthermore in PLS there is a critical criterion for analyzing segment-specific FIMIXPLS results. This criterion indicates the degree of all observations' classification and their estimated segment membership probabilities $P i k$ on a case-by-case basis and subsequently reveals the most appropriate number of latent segments for a clear-cut segmentation:

$$
\mathrm{EN} \kappa=1-\frac{\left[\sum_{i} \sum_{k}-P i \kappa \ln (\text { Pi })\right]}{I \ln (\kappa)}
$$

(Ringle et al., 2010a: 32-33; Ringle et al., 2010b:200). Since amount of EN is more than 0.5 (0.597319) in the FIMIX-PLS test, segmentation of samples that is policy makers and academicians have a clear segmentation for results estimation.

\section{Conclusion}

As results explain the purposes of this research that is confirmation of public policy analysis model of Iran confirmed and in this base we can predict that public policy analysis considers three dimensions of analysis according policy stages and proceeds it, as 'Formulation analysis' and 'Implementation analysis' and 'Evaluation analysis' compose dimension of public policy analysis model and 'Evaluation analysis' have high (weight) importance in public policy analysis decisions. Also this research found out relationships between public policy analysis model effects that these are: "formulation analysis" have direct effect on "public policy analysis" and 'implementation analysis' but "implementation analysis" and "evaluation analysis" sequently affects public policy analysis, that is, formulation analysis makes effect on implementation analysis and then implementation analysis have effect on evaluation analysis and eventually evaluation analysis have effect on public policy analysis. Also formulation analysis influences evaluation analysis. The results also confirm effect of policy making system's prerequisites on public policy analysis. Also cause-effect relationship indicates effect of public policy analysis criteria on formulation analysis. Other results demonstrate significance and effects of indicators of each constructs of model that these indicators based on their importance (weight) in public policy analysis sequently are: 'Evaluation thinking', 'Problem structuring', 'Goal setting', 'Law making', and 'Implementation thinking' which have influence on Formulation Analysis. Indicators of 'Policy implementation', 'Evaluation of implementation' and 'Act analysis' have effect on Implementation Analysis. Indicators of 'Implementation evaluation', 'Policy/law evaluation', and 'Meta evaluation' have impact on Evaluation Analysis. Indictors of 'Public interest', 'Realness', 'Feasibility', 'National interests', 'Public satisfaction', 'Social justice' and 'Costbenefit/Effectiveness analysis' compose indicators of Criteria construct and have effect on 
Formulation Analysis. Indicators of 'Active participation of stakeholders', 'Policy research' 'intelligent information' comprise Prerequisites construct which have effect on policy analysis. This research assumed policy cycle as a frame of analysis and has moved forward public policy analysis concentration two steps ahead, that is, implementation analysis and evaluation analysis in detail to complete analysis cycle. Also this model because of functional approach to policy analysis and extract most important factors of policy analysis in all stages is a new approach. It indicates that a policy for measurability acquires to analysis of whole of a policy stages and analysis starts from formulation analysis, if policy implemented or is implementing, carries out implementation analysis and finally evaluation analysis carries out for implemented policies. Thus we can define: public policy analysis is a function which carries out through process of formulation analysis, implementation analysis and evaluation analysis with use of multidisciplinary sciences.

\section{Acknowledgment}

I am grateful for all helps and comments to this research.

\section{References}

Chin, W. W. (2010) How to write up and report PLS analyses. In V. Esposito Vinzi, W. W. Chin, J. Henseler, \& H. Wang (Eds.) Handbook of partial least squares: Concepts, methods and applications (pp. 655-690). Berlin: Springer-Verlag.

Coelho, P. S.; Henseler, J. (2012) Creating customer loyalty through service customization .European Journal of Marketing. 46(3), 331 - 356

Dunn, W. (2007) Public Policy Analysis: An Introduction. Prentice- Hall. Englewood Cliffs.

Duarte, P. A. O.; Raposo, M. L. B. (2010) A PLS Model to Study Brand Preference: An Application to the Mobile Phone Market. In V. Esposito Vinzi, W. W. Chin, J. Henseler, \& H. Wang (Eds.) Handbook of partial least squares: Concepts, methods and applications (pp. 449-486). Berlin: Springer-Verlag.

Dye, T. R. (2008) Understanding Public Policy. Prentice Hall.

Fischer, F., Miller, G. J. \& Sidney, M. S. (2007) Handbook of Public Policy Analysis: Theory, Politics, and Methods.CRC Press Taylor \& Francis Group.

Glaser, B. G (2002) Constructivist Grounded Theory?. Forum: Qualitative Social Research, $3(3)$.

Götz, O., Liehr-Gobbers \& K; Krafft, M. (2010) Evaluation of Structural Equation Models Using the Partial Least Squares (PLS) Approach. In V. Esposito Vinzi, W. W. Chin, J. Henseler, \& H. Wang (Eds.) Handbook of partial least squares: Concepts, methods and applications (pp. 691-711). Berlin: Springer-Verlag.

Hair, J., Ringle, C. M., \& Sarstedt, M. (2011). PLS-SEM: Indeed a Silver Bullet . Journal of Marketing Theory and Practice. 19(2), 139-151.

Hanafizade, P.; Rahmani, A. (2010) Methodology of Multidimensional Structures. Tehran. Termeh Publication.

Henseler, J. (2010) On the convergence of partial least squares path modeling algorithm. Comput Stat, 25, 107- 120. Open access at www.springerlink.com

Henseler, J., Ringle, C. M., \& Sinkovics, R. (2009) The use of partial least squares path modeling in international marketing . Advances in International Marketing, 20, 277319.

Henseler, J; Sarstedt, M. (2012) Goodness of fit indecies for partial least squares path modeling. orginal paper, springer.

Höck, C., Ringle, C. M. \& Sarstedt, M. (2010) Management of multi-purpose stadiums: 
importance and performance measurement of service interface. International Journal of Services Technology and Management, 14(2/3), 188-207.

Höck, M; Ringle, C. M. (2010). Local strategic networks in the software industry: an empirical analysis of the value continuum. International Journal of Knowledge Management Studies, 4(2).

Knoepfel, P., Larrue, C., Varone, F. \& Hill, M. (2007) Public Policy Analysis. The Policy Press.

Kraft, M. F.; Furlong, S. R. (2010) Public Policy: Politics, Analysis, and Alternatives. CQ Press.

Morgan, M., Rein, M. \& Goodin, R. E. (2006) The Oxford Handbook of Public Policy. Oxford University Press.

Parsons, W. (2005) Public Policy: An introduction to the theory and practice of policy analysis. Edward Elgar.

Parsons, W. (2006) Policy Analysis in Britain. In Fischer, Frank\& Miller, Gerald J.\& Sidney, Mara. Handbook of Public Policy Analysis: Theory, Politics, and Methods. CRC Press Taylor \& Francis Group.

Ringle, C. M., Sarstedt, M. \& Mooi, E.A. (2010a) Response-Based Segmentation Using Finite Mixture Partial Squares: Theoretical Foundations and an Application to American Customer Satisfaction Index Data. In R.Stahlbock, S.F.Crone \& S.Lessman(eds). Data Mining. Annals of Information Systems 8. Springer science Business Media.

Ringle, C. M., Wende, S.\& Will, A. (2010b) Finite Mixture Partial Least Squares Analysis: Methodology and Numerical Examples. In V. Esposito Vinzi, W. W. Chin, J. Henseler, \& H. Wang (Eds.) Handbook of partial least squares: Concepts, methods and applications (pp. 195-218). Berlin: Springer-Verlag.

Ringle, C. M., Wende, S. \& Will, A. (2010) SmartPLS 2.0. Available online at: http://www.smartpls.de

R.K. S. (2010) Public Policy Art and Craft of Policy Analysis. PHI Learning Private Limited. New Delhi.

Ruiz,D. M., Gremler, D. D., Washburn ,J. H. \& Carri'on,G. C. (2010) Reframing Customer Value in a Service-Based Paradigm: An Evaluation of a Formative Measure in a Multiindustry, Cross-cultural Context. In V. Esposito Vinzi, W. W. Chin, J. Henseler, \& H. Wang (Eds.) Handbook of partial least squares: Concepts, methods and applications (pp. 535-566). Berlin: Springer-Verlag.

Stan,V. ; Saporta, G. (2010) Conjoint Use of Variables Clustering and PLS Structural Equations Modeling. In V. Esposito Vinzi, W. W. Chin, J. Henseler, \& H. Wang (Eds.) Handbook of partial least squares: Concepts, methods and applications (pp. 235-246). Berlin: Springer-Verlag.

Vinzi, V. E., Chin, W. W., Henseler, J. \& Wang, H. (2010) Handbook of Partial Least Squares:Concepts, Methods and Applications. Springer. Open access at http://www.springer.com/series/7286

Weimer, D. L.(1992) The Craft of Policy Design. Policy Studies Review, 11(3/4).

Weimer, D.L.; Vining, A. R. (2011) (5ed).Policy Analysis. Longman.

Wildavsky, A. (1979) The Art of Analysis. In Shafritz, J. M., Layne, K. S. \&Borick, C. P. Classics of Public Policy. United States. Pearson-Longman.

Wilson, B. (2010) Using PLS to Investigate Interaction Effects Between Higher Order Branding Constructs. In V. Esposito Vinzi, W. W. Chin, J. Henseler, \& H. Wang (Eds.) Handbook of partial least squares: Concepts, methods and applications (pp. 621-652). Berlin: Springer-Verlag. 